\title{
TRIBOLOGICAL BEHAVIOR OF COMPOSITE-STEEL ON ROLLINGISLIDING CONTACTS FOR VARIOUS LOADS
}

\author{
M. Ando ${ }^{1}$, J. Sukumaran ${ }^{2}$ \\ ${ }^{1}$ Szent István University, GÉTI, Páter Károly utca 1. 2100 Göldöllő, Hungary \\ ${ }^{2}$ University of Gent, Department of Mechanical Construction and Production, Sint-Pietersnieuwstraat, 41, \\ 9000 Gent, Belgium
}

\begin{abstract}
Composites have replaced metals in the bearing industry for the exclusive performances from its properties were it can accommodate resins, fabrics and additives. Roll-slip is common behaviors in application were non-conformal contact exhibits like bearings, rollers and cams. Two elements control the tribological behavior of the material which is the rolling and the sliding element. Composite-steel contacts were tested using a twin-disc setup with open tribo-system to study the influence of load on the frictional behavior of the polymer composites. The contacts were tested with four different loads under $20 \%$ slip ratio for a regular interval of time. The curves from the friction force with respect to different loads follows a tendency of linear increase in friction force were the rolling resistance is the dominating mechanism. For the given condition the macro level investigations shows the absence of transfer layer on the steel counterparts. The tendency of the friction curve and the micrograph explicitly deliberates the involvement of abrasion and adhesion in the harder polymer from metal counterpart. The temperature variable is isolated in case of the above research. The examination of the contact surface reveals the formation of craters on the junction of polymer and textile.
\end{abstract}

Keywords Effect of the load, rolling/sliding, composites-steel non conformal contact

\section{INTRODUCTION}

Composite-steel pairs are normally used in dry running condition where high strength and internal lubrication are necessary. Generally, composites used in tribological applications were examined from the perspective of fillers and fibers [1, 2]. Considering the tribological properties, Fibers aid to the friction behaviour of the composites. Studies with respect to the fiber orientation resulted in instabilities on the coeffcient of friction [3].

As the requirements are achieved by the combination of fibers, resins and filler materials at various proportions [3]. Most of the researches studying the tribological behaviour of composites are focused on sliding. Various standards like pin-on disc, pin on ring and block on drum are used to evaluate the sliding phenomenon. Previous results from pin-on-disc on polyester composites has produced a rapid increase during the initial period of sliding due to factors like plastic deformation, contact area, and the intrinsic property of the composite material [4]. In these kind of testing the tendency of the curve changes with respect to the mechanism involved where either plastic deformation or adhesion determines the friction behaviour [3]. However, the use of composites in rollers, gears and bearings has rolling component together with sliding to have the roll-slip phenomenon which is never studied. In such a case simultaneous occurrence of both the mechanism (adhesion, plastic deformation) creates difficulties to segregate the influence of individual components (rolling/sliding) over friction behaviour. Moreover, the presence two mechanisms simultaneously produces different topographies of contact surface. Thus the contact condition changes with respect to the used model producing incomparable results. A close standard to test the rollslip of composite-steel pair is the twin-disc model where only limited researches has been done for polymer - metal [5-8].

In most of the tribological investigations the parameters is varied to place the material in the suitable application range where velocity and load are the most common parameters $[4,9,10]$. From the fundamentals it is well known that load has a significant effect on the friction behaviour of the material. Liu et al on using different materials to investigate the influence of load on the tribological characteristics has proved that the friction force increases linearly with increasing load on using similar materials [11]. The difference between the material exists in the rate of increase of friction force to the normal force proves that most of the material has similar tendency as the effect of load. 
In the current research an open tribo system is used to study the friction behaviour of composite-steel pairs under rolling/sliding conditions. Influencing factors like surface roughness or the composite pair, frictional heating and transfer film are suppressed by a specially developed program. Images from the contact surface are used to identify the dominating mechanisms involved in the friction process.

\section{MATERIALS AND METHODS}

On testing the composite-steel pair for roll-slip commercially available polyester composites (Orkot) is tested against $40 \mathrm{CrMn}$ tool steel. Orkot is used as a bearing material in marine applications, the composite itself is impregnated with polyester resin and PTFE. Tests performed on Orkot against steel at $15 \mathrm{MPa}$ has proven results having co-efficient of friction 0.13 (from datasheet). Material properties for both the materials are given in Table 1.

Table 1. Materials properties

\begin{tabular}{|l|c|c|}
\hline Properties & 40CrMn & Orkot \\
\hline Yield strength [MPa] & 415 & 55 \\
\hline Young's modulus [GPa] & 205 & 3.3 \\
\hline Impact Strength (Charpy) $\left[\mathrm{kJ} / \mathrm{m}^{2}\right]$ & 590 & 122 \\
\hline Hardness & $220 \mathrm{HB}$ & 100 Rockwell M \\
\hline Maximum allowable service temp. $\left[{ }^{\circ} \mathrm{C}\right]$ & - & 130 \\
\hline
\end{tabular}

To modelling the roll/slip phenomenon the twin-disc setup is the appropriate test device. On testing roll-slip a slip ratio will be involved which is the rolling to sliding ratio achieved by having different speeds fpor two disc. But, in the current setup both the shaft rotates at same speed and hence the required slip ratio is achieved by changing the diameter of the test material and the counterface material. In the used parameter the diameter of the polymer wheel was $120 \%$ compared to the steel wheel $(100 \%=74.93 \mathrm{~mm})$, which means the slip ratio is $20 \%$. Image of the twin disc set-up is shown in Figure 1 . Under the measurement was used online data acquisition system (Lab View). The friction torque was measure online using a torque meter (4 - Lorenz Messtechnik DR-20-type) attached to the shaft of the counterface material. The temperature with infra red sensor (3) $180^{\circ}$ away from the instant of contact point on the polymer wheel. Dead weights are used (5) to achieve constant normal force along the measurement. The speed of the two shaft controlled online.

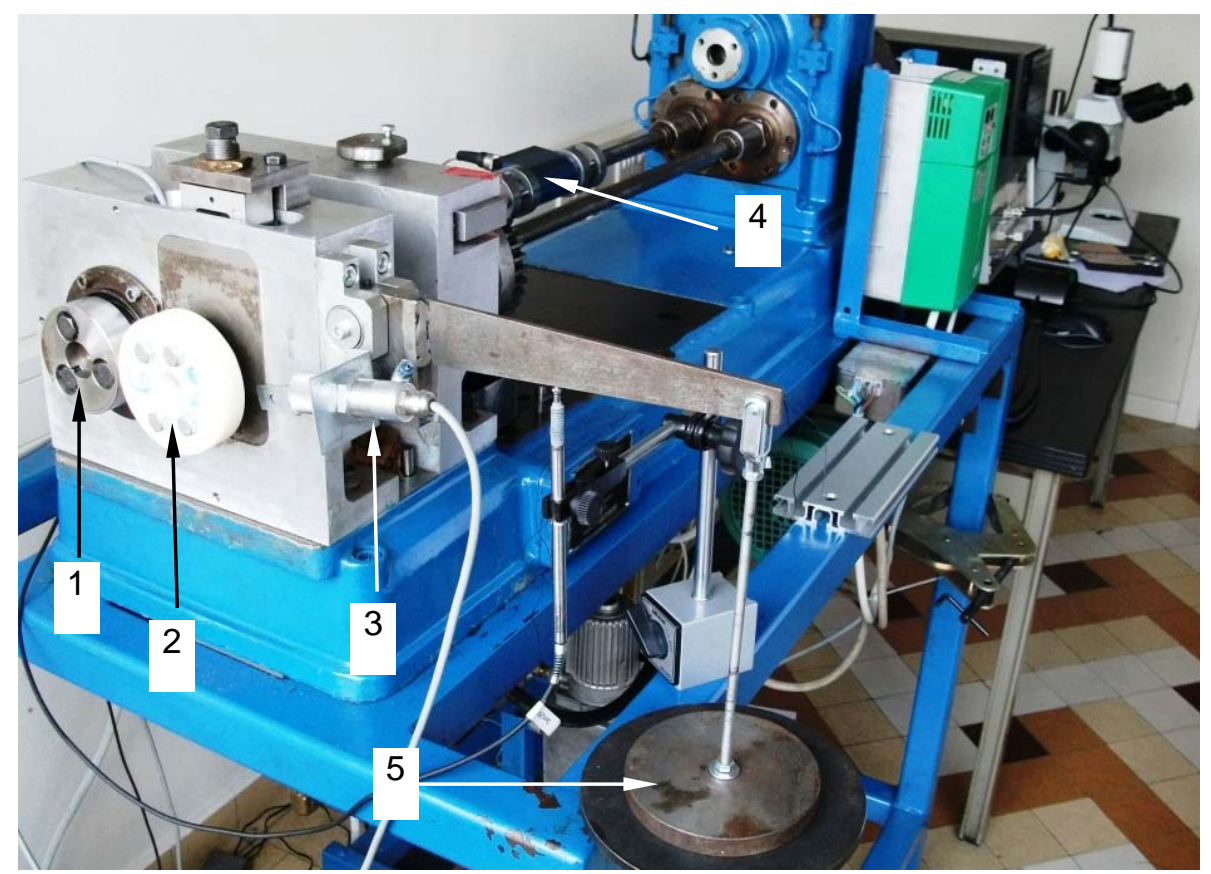

Figure 1. Twin-disc set-up to modelling rolling/sliding 
Four different dead weights are used to study the effect of the load on the friction behaviour of the composite-steel pair. The applied normal load and the corresponding contact mean and maximum contact pressure for a contact zone is given in Table 2.

Table 2. Show the normal force, Hertzian pressure and contact zone for composite-steel pair

\begin{tabular}{|c|c|c|c|}
\hline $\begin{array}{c}\text { Applied normal } \\
\text { force [N] }\end{array}$ & $\begin{array}{c}\text { Maximum } \\
\text { pressure [MPa] }\end{array}$ & $\begin{array}{c}\text { Mean pressure } \\
\text { [MPa] }\end{array}$ & $\begin{array}{c}\text { Contact area } \\
{[\mathbf{m m} \times \mathbf{m m} \text { ] }}\end{array}$ \\
\hline 61 & 77.23 & 60.66 & $0.126 \times 8$ \\
\hline 111 & 104.18 & 81.83 & $0.170 \times 8$ \\
\hline 161 & 125.47 & 98.55 & $0.204 \times 8$ \\
\hline 210 & 143.30 & 112.55 & $0.233 \times 8$ \\
\hline
\end{tabular}

A running in of 5 minutes is used prior to data collection, a test duration of 2 minutes is used at low and high speed condition. Every parameter was measured five times to check for the repeatability. Two different speeds $10 \mathrm{rpm}$ (low) and $700 \mathrm{rpm}$ (high) are used along with the different loads. All the tests are conducted at dry running condition (because of the internal lubrications e.g. PTFE). Image of the contact surface is acquired before and after the measurement using Olympus SFX microscope and QiCAM video camera.

\section{RESULT AND DISCUSSION}

The current research was focused on studying the tribological behaviour of composite metal pair on dry running condition. The aim of the experiments is to identify the boundary for friction behaviour under ideal condition without the influence of frictional heating and the transfer layer. The Figure 2 . shows the results using the same parameters for five time $(10 \mathrm{rpm})$. It is clear from the plotted curve that the repeatability of the test are good where the curves follow the same pattern and line close to each other.

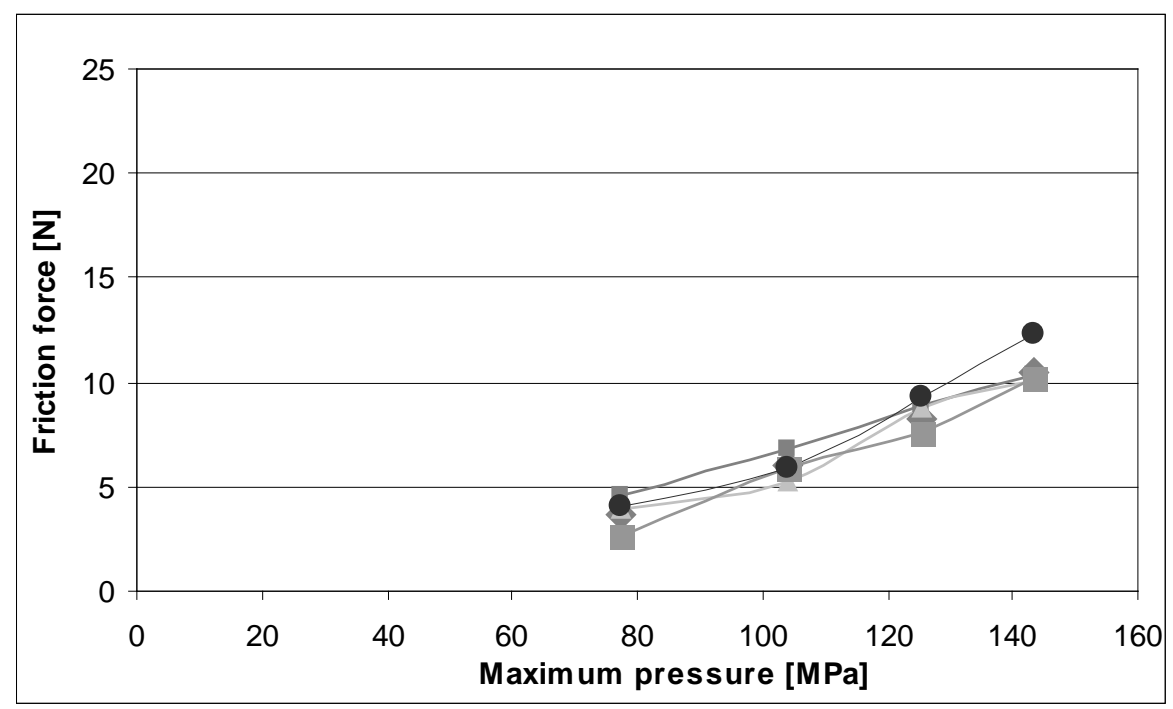

Figure 2. Friction force at low velocity

Curves were also plotted for two different speeds with friction force as a function of maximum pressure. Figure 3. illustrates the friction force with the fitted linear curve also having an error of $\pm 2 \sigma$. From the plot a linear cure is the best fit to describe the tendency of the curve. But one should keep in mind that this function is valid from $75 \mathrm{MPa}$. The lower limit of contact pressure for the operating condition is important, because if the material is tested with low loads for e.g. $20 \mathrm{MPa}$ maximum pressure it causes less than zero friction force (from this trend lines). Negative friction force cannot be achieved since there is always a friction force involved due to sliding and also a rolling resistance as well. The normal force has huge influence to the rolling resistance which is due to the intrinsic property of the material. In case of Orkot composite a relatively large young modulus (because the fibers) reduces the rolling resistance on comparing with a common engineer polymer. The Table 3. contains the equation from the curve fitting of the measured points. 


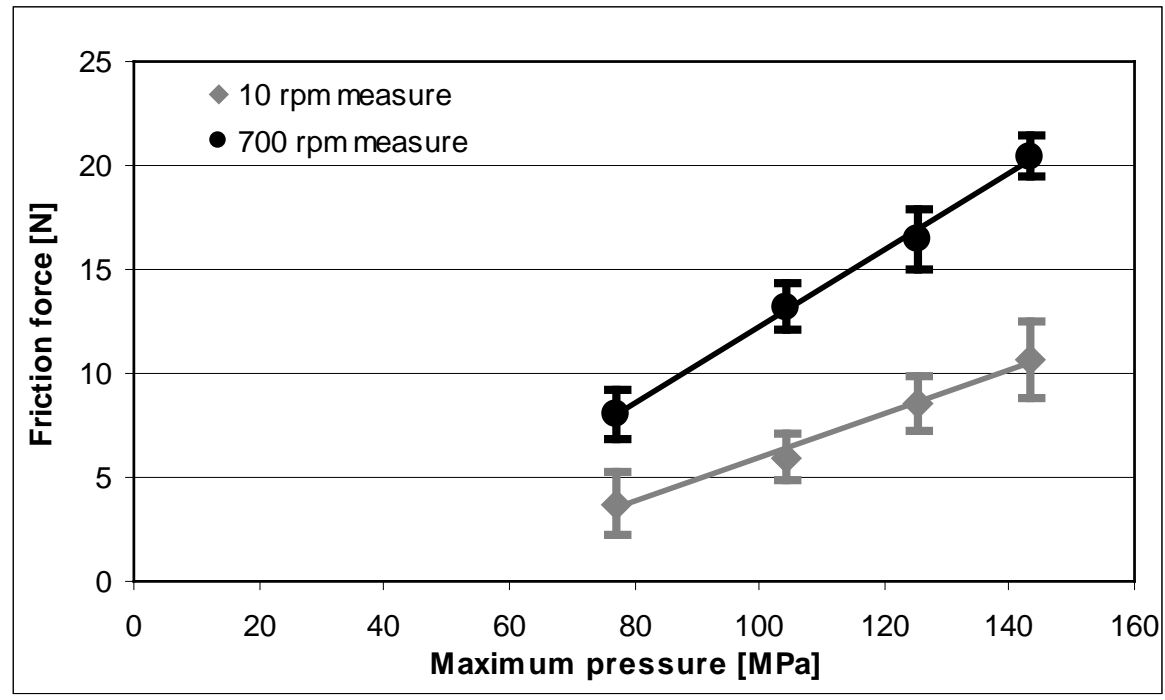

Figure 3. Effect of the pressure to the friction force

Table 3. Equations of the fitted curves and their $R^{2}$ values

\begin{tabular}{|l|l|l|}
\hline Speed & Equation & $\mathbf{R}^{2}$ value \\
\hline $\mathbf{1 0} \mathbf{~ r p m}$ & $F=0.106 \cdot p-4.690$ & 0.9323 \\
\hline $\mathbf{7 0 0} \mathbf{~ r p m}$ & $F=0.184 \cdot p-6.134$ & 0.9831 \\
\hline
\end{tabular}

In case of high speed the inclination of the curve is almost two times bigger than the low speed. Where it is better to reduce the contact pressure (used bigger dimensions) on high speeds which leads to energy saving by having reduced friction force. But in case of low speed the larger geometry doesn't cause considerable saving.

Figure 4. shows the friction force as a function normal force for low and high speed condition. The tendency of the friction curve for the corresponding normal forces follows a linear pattern which is same as that of the plot used in the friction force against the Hertzian pressure. Here, there are difference of the slope too. Important change that if choose smaller normal force (e.g $10 \mathrm{~N}$ ), the friction force will positive values (based on the fitted curves). Because of this, the fitted curves are possible to describe the phenomenon in lower (e.g. $30 \mathrm{~N})$ and higher (e.g. 230N) interval also.

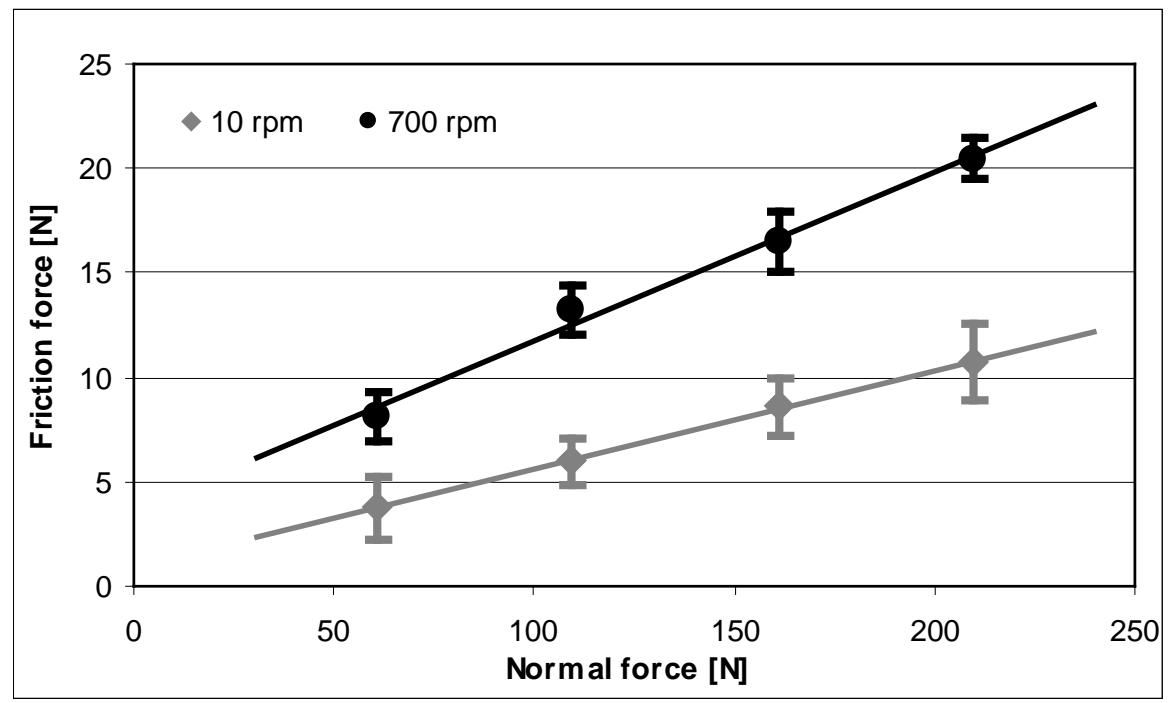

Figure 4. Effect of the normal load to the friction force

Because the linear effect there it is possible that the friction and the rolling coefficient are constant. Usually in case of high loads the adhesion properties are considered to be very important. But from the obtained 
result didn't show considerable change (no blending in the results), which mean there is no vital effect of the adhesion. May be the presence of PTFE could have possibly reduced the adhesion effect. To clearly study the rolling and the sliding coefficient values further experiments needed.

Tribological tests on evaluating the friction characteristics uses temperature to explain the tendency as a outcome of frictional heating. In the current research the influence of frictional heating is made negligible by allowing enough cooling time between two measurements and by using the cleaning agents which removes the induced heat in the test cycle. On measuring the temperature of the contact surface from the composite disc temperature of $24 \pm 2^{\circ} \mathrm{C}$ was observed which is close to the room temperature. Even with online monitoring system the measured surface temperature fluctuates a little. The temperature of the contact surface has reached a maximum value of $26^{\circ} \mathrm{C}$ which is very low considering the earlier researches on rolling/sliding contacts of polymers, where the increase in temperature was up till $80^{\circ}$. Investigation on the image of the contact surface also briefs that there is no deposit of polymer on the counterface material.

\section{MICROGRAPH}

Pictures of the contact surface were made using Olympus SRZ microscope. Images were captured before and after every test cycle for all loads. Figure 5(a) show the initial surface before testing where the fibers are not really visible to make potential change in the friction characteristics. But on the consecutive testing the matrix tends to be removed and scale like surface morphology is seen showing the fibers leaving the matrix. The machine mark from the tool steel is also visible on Figure 5.
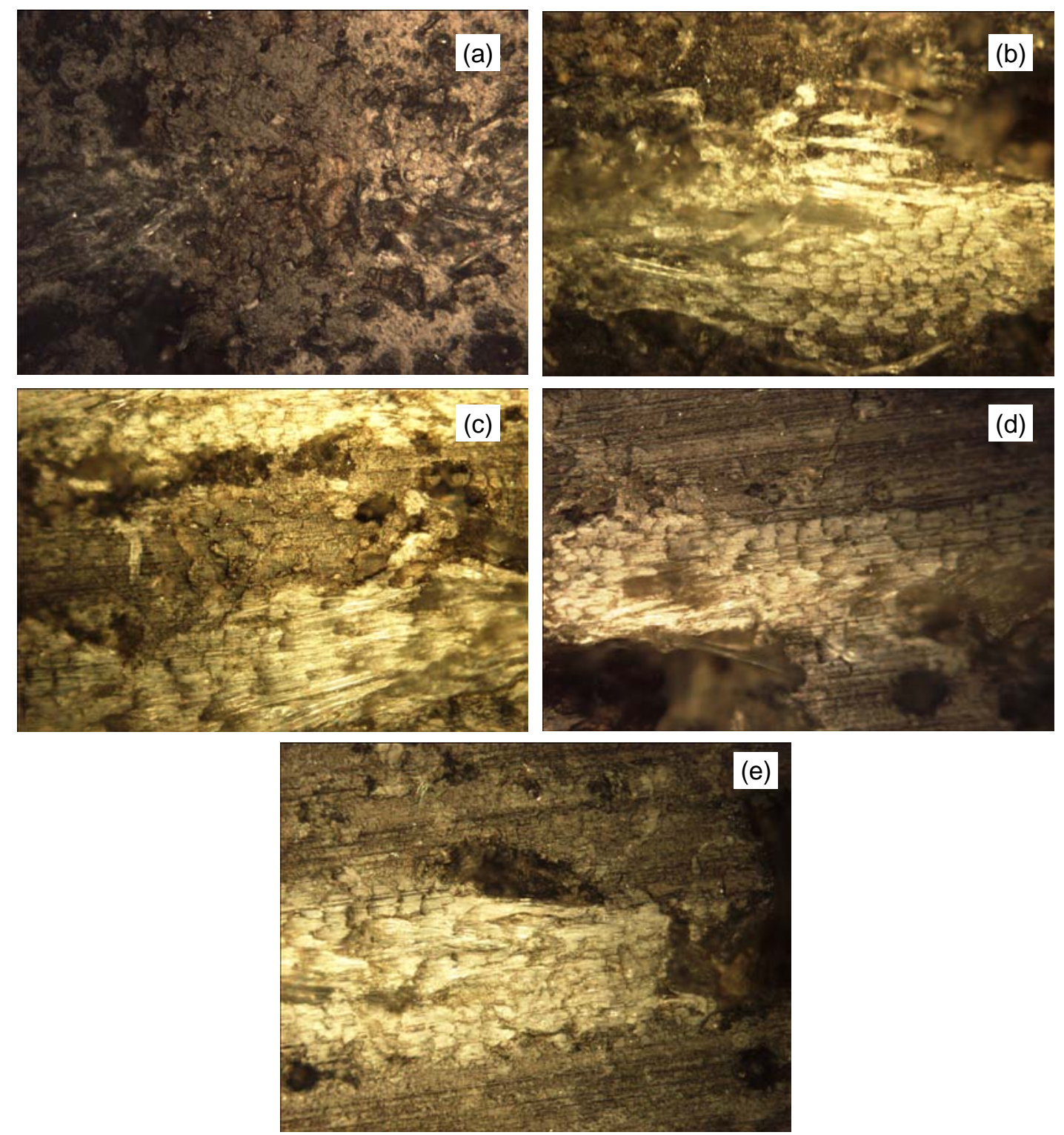

Figure 5. Contact surface before test (a), after test in case of $61 \mathrm{~N}(\mathrm{~b}), 111 \mathrm{~N}(\mathrm{c}), 161 \mathrm{~N}(\mathrm{~d})$ and $210 \mathrm{~N}(\mathrm{e})$ 
The limited experiment time cause limited wear also. From $61 \mathrm{~N}$ to $210 \mathrm{~N}$ (Figure 5 . b-e) the surface topography is almost the same. The rolling leads to periodical deformation, which is actually little displacement close to the surface. This displacement breaks the joints between the polyester matrix and the textile. For this effect the matrix can easy remove that fields where the textile is close to the surface. This is the reason, that after the experiments the textile structure becomes visible over the polymer surface. Effect of the load just the dept of the craters on the border between the textile and the matrix. Because the high normal load (and the high maximum contact pressure) larger displacement exhibits, which destroy the structure beneath the layers also.

\section{CONCLUSION}

Polymer composite which is widely used in the bearing industry is tested for the influence of load on the friction behaviour under low and high speed condition. On both high and low speeds the friction force showed same tendency having a linear increase in friction force for increasing load. The rate of increase in friction force is much sensitive on high speed. The linear curves are well fitted, because in this system there is no effect of the temperature and the other conditions were also steady. Based on the results the PTFE content helps the composite to avoid the adhesion effect also. If the applications has high contact speed, it is worth to use larger dimensions to reduce the contact pressure. The new geometry leads to energy saving applications, but in case of low loads this saving relatively less. From low load $(61 \mathrm{~N})$ the periodical stress lead cracks, craters and visible textile of the surface. High load only increases the depth of the cracks and craters.

\section{REFERENCES}

[1] Srivastava V.K., Pathak J.P., Friction and wear properties of bushing bearing of graphite filled short glass fibre composites in dry sliding, Wear 197(1-2), 145-150, 1996.

[2] Kishore, Sampathkumaran P., Seetharamu S., Thomas P., Janardhana M., A study on the effect of the type and content of filler in epoxy-glass composite system on the friction and slide wear characteristics, Wear, 259(1-6), 634-641, 2005.

[3] Quintelier J., Online wear monitoring of polymer matrix composites with advanced measurement techniques, Ph.D Thesis, Gent University, 2007.

[4] Myshkin N.K., Petrokovets M.I., Kovalev A.V., Tribology of polymers: Adhesion, friction, wear, and mass-transfer, Tribology International, 38(11-12), 910-921, 2005.

[5] Hooke C.J., Kukureka S.N., Liao P., Rao M., Chen Y.K., The friction and wear of polymers in nonconformal contacts, Wear, 200(1-2), 83-94, 1996.

[6] Kukureka S.N., Chen Y.K., Hooke C.J., Liao P., The wear mechanisms of acetal in unlubricated rolling - sliding contact, Wear, 185(1-2), 1-8, 1995.

[7] Gordona D.H., Kukureka S.N., The wear and friction of polyamide 46 and polyamide 46/aramid-fibre, composites in sliding-rolling contact, Wear, 267(1-4), 669-678, 2009.

[8] Chena Y.K., Modib O.P., Mhaya A.S., Chrysanthou A., O'Sullivan J.M., The effect of different metallic counterface materials and different surface treatments on the wear and friction of polyamide 66 and its composite in rolling-sliding contact, Wear, 255(1-6), 714-721, 2003.

[9] Su F., Zhang Z.Z., Guo F., Men X.H., Liu W.M., Friction and wear properties of fabric/phenolic composites with plasma treated-hybrid glass/PTFE fabric, Composites Science and Technology, 67(6), 981-988, 2007.

[10] Gopal P., Dharani L. R., Blum F. D., Load, speed and temperature sensitivities of a carbon-fiber reinforced phenolic friction material, Wear, 181-183(Part 2 March), 913-921, 1995.

[11] Liu Y., Schaefer J.A., The sliding friction of thermoplastic polymer composites tested at low speeds, Wear, 261(5-6), 568-577, 2006. 